\title{
“HUACA", UN CONCEPTO ANDINO MAL ENTENDIDO
}

\author{
"HUACA", A MISUNDERSTOOD ANDEAN CONCEPT
}

\author{
César Itier ${ }^{1}$
}

\begin{abstract}
"Huaca" es hoy una de las palabras claves del vocabulario etnohistórico y arqueológico sobre los Andes. A partir de una lectura acrítica de los Comentarios reales de Garcilaso, se suele considerar que este término quechua significaba "objeto o lugar sagrado". Examinando las fuentes históricas, así como la información lingüística moderna, este artículo muestra que "huaca" (wak'a) significó 'partidura' y que, en el ámbito religioso, dicho término designó piedras transportables consideradas como desprendimientos o duplicaciones de un ancestro mítico residente en un cerro. Por extensión, wak'a se aplicaba también al santuario que albergaba dichas piedras, al mismo ancestro divino y a amuletos de piedra que emanaban de él. Numerosos indicios sugieren que el culto de las piedras huacas es de origen inca.
\end{abstract}

Palabras claves: religión, inca, quechua, huaca.

\begin{abstract}
"Huaca" is one of the key words used in the ethnohistorical and archaeological vocabulary about the Andes today. From an uncritical reading of Garcilaso's Royal Commentaries, this Quechua term is often considered to mean "sacred object or place". By examining historical sources as well as modern linguistic information, this article shows that "huaca" (wak'a) meant 'split' and that, in the religious field, this term designated transportable stones considered as detachments or duplications of a mountaindwelling mythical ancestor. By extension, wak' a also applied to the sanctuary that housed these stones, to the same divine ancestor and to stone amulets emanating from him. Numerous indications suggest that the cult of the huaca stones is of Inca origin.
\end{abstract}

Key words: Religion, Inca, Quechua, huaca.

Las fuentes históricas señalan que, entre los principales cultos antiguamente practicados en el Perú, se hallaba el de unas entidades llamadas "huaca(s)" en quechua y en aimara. La investigación moderna suele definir este término como 'objeto o lugar sagrado' y considera que, bajo la categoría de "huaca", los andinos sacralizaban una gran diversidad de seres: rocas, cerros, manantiales, cuevas, estatuillas, edificios, etc. La atribución a "huaca" del significado susodicho no procede de un estudio crítico de las fuentes, sino directamente de una afirmación de Garcilaso, según el cual huaca "quiere decir cosa sagrada" (Comentarios reales, lib. II, cap. 4).

A continuación, retomaremos la cuestión, fundamental para la comprensión de la antigua religión andina, de lo que era un(a) huaca. Examinaremos primero los diversos referentes del término en las fuentes de los siglos XVI y XVII, así como los que tiene en las variedades actuales del quechua y del aimara. Reconstruiremos luego el significado antiguo de "huaca" y la lógica semántica y cultural que determinaba su aplicación a distintas entidades. Ello nos llevará a abordar, por lo menos en sus aspectos fundamentales, el problema de la posición de los huacas dentro del antiguo panteón andino, así como el de las funciones y del origen histórico de su culto.

\section{La Interpretación Garcilasiana}

Los investigadores modernos suelen hacer suya la siguiente afirmación de Garcilaso según la cual "huaca" "pronunciada la última sílaba en lo alto del paladar" -es decir wak'a, según la forma cuzqueña del término- "Quiere decir cosa sagrada, como eran todas aquellas en que el demonio les hablaba, esto es, los ídolos, las peñas, piedras grandes o árboles en que el enemigo entraba para hacerles creer que era dios" (Comentarios reales, lib. II, cap. 4). Garcilaso enumera las entidades que los peruanos calificaban de "huacas": los templos y los sepulcros

$1 \quad$ Institut National des Langues et Civilisations Orientales (INALCO), Paris, France. cesar.itier@inalco.fr

Recibido: noviembre 2019. Aceptado: julio 2020. 
-y en general todo lugar donde los sacerdotes tenían "comunicación con el demonio"-, toda entidad natural de forma o tamaño llamativos (p.ej., guijarros de apariencia extraña, vegetales de peculiar belleza o animales que inspiraban terror, como la anaconda), los mellizos -y también su madre-, los niños que nacían con deformaciones físicas, los manantiales caudalosos y los cerros altos (lib. II, cap. 4). Según el Inca, todos estos seres tenían en común el haber sido "señalado[s] de naturaleza", cualidad que les merecía el calificativo de "huacas" (lib. II, cap. 4). El cronista sintetiza su interpretación como sigue: "A todas estas cosas y otras semejantes llamaron huaca, no por tenerlas por dioses ni adoradas, sino por la particular ventaja que hacían a las comunes; por esta causa las miraban y trataban con veneración y respeto." (lib. II, cap. 4, las cursivas son nuestras). Garcilaso consideraba por lo tanto "huaca" como un calificativo aplicable a cualquier entidad que, por su apariencia extraña, suscitaba la reverencia de un pueblo propenso, según él, a reconocer en la naturaleza manifestaciones de la grandeza divina. $\mathrm{La}$ intención fundamental del Inca es afirmar que, para los peruanos, las huacas no eran "dioses", es decir entidades a las que se daba "adoración", sino simples objetos de "veneración", conforme a un panteísmo natural -es decir no demoníaco- y de baja intensidad. De esta forma, el cronista denunciaba la interpretación común según la cual "los Incas y sus vasallos adoraban por dioses todas aquellas cosas que llaman huaca" (lib. II, cap. 5). Para Garcilaso, el demonio no fue el inspirador del sentimiento religioso indígena, aunque por supuesto el "enemigo" supo sacar de él un provecho puntual, manifestándose en algunos de estos objetos e induciendo a que algunos indios los adoraran como divinidades. Según él, los incas no reconocieron por dioses más que a Pachacámac, el Sol, la Luna y las estrellas -que no eran huacas-, dando primacía al primero, a quien consideraban como primer motor invisible (Duviols 1971:27).

$\mathrm{Al}$ afirmar que "huaca" no era el nombre de una categoría de divinidades, Garcilaso se oponía a toda la tradición interpretativa anterior y a la equivalencia que se había establecido entre "huaca" y el concepto cristiano de "ídolo". Garcilaso mencionó esta equiparación al inicio de su larga disquisición sobre "huaca": "quiere decir ídolo, como Júpiter, Marte, Venus" (lib. II, cap. 4). Si bien la primera parte de esta aserción podría tomarse como una concesión al uso que los españoles solían hacer del término, la segunda parte (“como ...") impone otra interpretación, pues, al evocar a Júpiter, Marte y Venus, el Inca convierte "huaca" en un concepto filosófico reminiscente del misticismo astral de la Antigüedad: era huaca todo lo que inspiraba reverencia ante el sublime misterio de la Creación. De esa forma el concepto indígena cristalizaba, para Garcilaso, una intuición intelectual susceptible de conducir al monoteísmo. Por lo tanto, en la frase citada, el adverbio "como" no debe entenderse en el sentido de "por ejemplo", sino como una comparación: "huaca" era un "ídolo" en el mismo sentido en que los mencionados astros lo eran, según él, para los romanos, es decir en tanto que mediación concreta en la experiencia de lo divino, necesariamente invisible y uno. De hecho, en los capítulos que dedica a los cultos de los peruanos, el Inca -siempre atento a los significados referenciales del quechua- no incluyó los astros dentro de la categoría de "huaca". Para nuestro propósito es esencial tomar en cuenta que su interpretación de "huaca" como "cosa sagrada" o "señalada de naturaleza" está profundamente sesgada por su perspectiva teológica y apologética. Además, como se verá a continuación, no se compatibiliza con la información proporcionada por otras fuentes.

\section{Primeras Definiciones}

La equivalencia "huaca" = "ídolo (peruano)" asoma ya en los testimonios de los dos primeros intérpretes de la religión andina, Juan de Betanzos y Domingo de Santo Tomás. Según el primero, "quiere dezir guaca adoratorio o ydolo" (2015 [1551]:126). El dominico, por su parte, ofrece en la parte quechua-español de su Lexicón una definición parecida: "Guaca templo de ydolos, o el mismo ydolo" (Santo Tomás 1994 [1560]:131r). La sección inversa confirma esta doble equivalencia: "Ydolo [=] guaca" y "Templo de indios generalmente [=] guaca". Según ambos testimonios, "guaca" designaba a la vez una divinidad material y el edificio en que se la conservaba. El hecho de que contenido y continente fueran designados mediante el mismo término sugiere que un templo no era, para los andinos, una estructura ontológicamente separada del ser albergado en él. Veremos más adelante que ambos habrían constituido una misma entidad.

En la primacía que Betanzos y Santo Tomás dan a la acepción de "templo" o "adoratorio", probablemente deba verse una consecuencia de la impresión que los grandes edificios cultuales y funerarios de la costa -y sobre todo las riquezas que encerraban- causaron en los españoles del siglo XVI. De hecho, los testimonios de las primeras décadas de la época colonial utilizan 
abundantemente el término "guaca" para referirse a ellos. Cieza de León, por ejemplo, señaló a "[1]os templos antiguos, que generalmente llaman guacas" (Cieza de León 1995 [1553]:185, cap. LVIIII). Las Casas también los mencionó: "En los Reinos llamados comúnmente del Perú, [...] se han encontrado y se encuentran todos los días, en los sepulcros antiquísimos de los muertos, llamados en su lengua 'Guacas', grandes y maravillosos tesoros de distintos objetos preciosos" (Las Casas 1992 [1565]:13). De esa forma, una acepción del término que, en quechua, era, como se verá ahora, secundaria y metonímica, se convirtió, en castellano peruano, en el nombre genérico de los edificios piramidales costeños.

\section{Las Piedras Huacas}

¿A qué se referían concretamente Betanzos y Santo Tomás con el término "ídolo"? Cristóbal de Albornoz, que descubrió muchas "huacas" en todo el Perú, en las décadas de 1560 y 1570, describió muy brevemente algunas de ellas; por ejemplo: "Rimac, guaca de los indios de Lima [...] era una piedra redonda" (Duviols 1967:34). Bartolomé Álvarez, acucioso investigador de la religión indígena, señala que "Todas estas uacas eran de piedra, por la mayor parte figuras de Ingas y de hombres principales, antecesores dellos" (Álvarez 1998 [1588]:75). Los procesos de idolatrías que se siguieron en el siglo XVII en la provincia de Cajatambo ofrecen descripciones relativamente precisas de lo que se llamaba "huaca", o calificaba de tal, en quechua ${ }^{1}$. En ellos, "huaca" designa piedras de tamaño mediano, en muchos casos antropomorfas, aunque esculpidas de modo parcial o alusivo. En el pueblo de Hacas, los ayllus Yanaqui y Quirca rendían culto a Caruayacolca y Caquiguaca, que "eran de piedra y de forma de persona" (Duviols 2003:403). En cambio, Raupoma y Choquerunto, huacas de los ayllus Guangry y Otuco, en el mismo pueblo, "eran dos piedras redondas de color de huebo de perdiz y resplandecian como unos gusanillos que llaman luzernas y en su lengua llipiac hina" (Duviols 2003:171). Otras piedras huacas tenían la forma de una cabeza humana cuyo aspecto horrorizó a los visitadores de idolatrías. En 1621 se descubrió cerca de Ocros "un adoratorio rodeado de cantería y en medio hecho un caracol, estaba su respetada y principal huaca [del pueblo viejo de Huacoy] llamada Llamoc, que era una piedra a modo de una calavera, tan pesada como fiera, que mirarla ponía horror" (Duviols 2003:740). Algunas de estas piedras eran zoomorfas, como en Santa María Magdalena, en la provincia de Huaylas, donde el aillu Pallauto veneraba la huaca Llámoc "que es de mármol, cuello y cabeza y pico de un ave, sin cola ni pies, labrado a modo de un escamado de piedra, a quien acompañaba su hermano Aurin, que era a modo de un cepo de piedra negra" (Duviols 2003:750). Otras estaban cubiertas de metal, como el huaca Musin, adorado por el ayllu Carampa del pueblo de Hacas, que era "vn ydolo de piedra redondo de metal el qual ydolo reconosieron y dijeron los dichos llamarse musinguaca" (Duviols 2003:457-458).

Las cartas annuas de los jesuitas inciden con frecuencia en que las piedras huacas se conservaban en santuarios situados en la parte alta de los cerros: "Otro tenia vna guaca que es una adoraçion muy antigua destos indios, en un alto çerro donde hacia subir a los pobres que engañaba, trepando por una cuerda y llevando en la voca lo que hauian de ofreçer, no sin grande peligro de la vida" (Polia Meconi 1999:207). Bartolomé Álvarez señala que "Estas uacas o ídolos las colocaban [...] en los más altos cerros y más extremados en disposición y en lo más dificultoso dellos" (Álvarez 1998 [1588]:74). Entre las numerosas huacas registradas por Albornoz en todo el Perú estaba el "Sarasara, es un cerro nevado y en él está una piedra del dicho nombre" (Duviols 1967:29).

Las piedras huacas eran transportables y no se deben confundir con los monolitos huancas, que eran más grandes y estaban hincados en el suelo (Duviols 2016b [1978], 2016c [1979]). Según Bartolomé Álvarez, el carácter móvil de las huacas se remontaba a un contexto de migración: "las llevaban cuando todo el pueblo se mudaba de una parte a otra buscando tierras donde vivir, hasta que hallaban donde asentar" (Álvarez 1998 [1588]:75). Según los agustinos de Huamachuco, "del Cuzco [el Inca] traxo munchos del linaje del ynga a guamachuco que heran del cuzco [...] quando estos vinyeron de antiguo tiempo traxeron vn ydolo o guaca que se llama topa llimillau pequeña y negra que pareçia plomada de albañir" (San Pedro 1992:185). Albornoz explica que la piedra llevada por un grupo de migrantes a su nuevo territorio era un sustituto de la huaca original y que se la vestía con la ropa de esta (Duviols 1967:170-171). Varios testimonios se refieren a estas piedras desplazadas de su lugar de origen y conservadas en estructuras subterráneas (Álvarez 1998:87, Duviols 2003:170171). Hace poco, un equipo de arqueólogos descubrió, en un pequeño santuario de las alturas de Huamanga 
(una importante zona de colonización inca), tres piedras que por sus características y contexto parecen corresponder a lo que las fuentes históricas llaman "huacas" (Meddens et al 2010; McEwan 2015). Se trata de una piedra trapezoidal de andesita roja, una piedra cónica de andesita blanca y una piedra en forma de creciente de andesita roja, de unos $40 \mathrm{~cm}$ de largo.

\section{Los Huacas, Hombres y Mujeres del Pasado}

En una época primordial, antes de ser piedras, las huacas fueron hombres y mujeres como los del presente. Arriaga señala que "todas las huacas principales tienen sus fábulas de que tuvieron hijos y fueron hombres que se convirtieron en piedra" (Arriaga 1999 [1621]:128). Entre otros muchos testimonios al respecto, se puede citar esta carta annua relativa a una misión en el corregimiento de Cajatambo en 1619:

Las fabulas que esta gente tiene de sus dioses son muchas y muy semejantes a las de los antiguos griegos y romanos dando razon del origen de sus Huacas y quien los convirtio en piedras. Dicen que en tiempos muy antiguos aun antes del Govierno de los Ingas todas las Huacas eran hombres y mujeres como los de agora. Pero que salio del Collao que es en el obispado del cuzco (otros dizen de la laguna de chucuito en el obispado de la paz que llaman de Titicaca) vn gran gigante dios de aquella tierra llamado Huari viraccocha [...], el qual por doquiera que pasaba convertia las Huacas en piedras"' (Duviols 2003:725).

Estas "fábulas" son precisamente las que narra la anónima relación quechua de Huarochirí, cuyo autor califica de huacas a Huallallu Carhuinchu, Pariacaca, Cuniraya, Cahuillaca, Chaupiñamca, Rucanacoto, Urpayhuachac y Macahuisa, entre otros protagonistas de su relato. Algunos de estos huacas eran hombres (Huallallu, Pariacaca, Cuniraya, Rucanacoto, Macahuisa), mientras que otros eran mujeres (Cahuillaca, Chaupiñamca y Urpaihuachac). Los procesos de Cajatambo también ofrecen ejemplos de huacas femeninos (p.ej., Duviols 2003:766). Los huacas -en adelante nos referiremos a ellos en masculino, pues pertenecían a ambos géneros- fueron, por lo tanto, los miembros prominentes de una primera humanidad.
Algunos declarantes de los procesos de Cajatambo reproducen fórmulas rituales que califican al Sol de padre de los huacas. Juan Guaraz, del pueblo de Pariac, por ejemplo, confiesa haber adorado "al Sol llamandolo punchau por ser padre y señor de todas las Guacas al qual le dize Inti yaya Punchauyaya Guaca chury [sic] yaya caymi cucac [sic] caymi azua caymi Zara caymi aca cayta micuy upiay" (Duviols 2003:268) ${ }^{2}$. El visitador de idolatrías Bernardo de Noboa observó que los habitantes del mismo pueblo "mochaban al sol llamandole punchao y padre de todas las Guacas y le diçen quando le mochan inti yaya Punchao yaya Guaca churiyoc yaya caymi coca azua Zara micuy cayta upiay (Duviols 2003:290) ${ }^{3}$. La expresión waka churiyuq puede interpretarse de dos maneras: como 'progenitor de los huacas (en general)' -como lo entendía Noboa- o como 'progenitor de los huacas (de nuestro pueblo)'. La información disponible aboga a favor de la segunda interpretación. En efecto, los aillus llacuaces de Hacas, en la misma provincia de Cajatambo, veían en Llibiac (lliwyaq '[cielo] despejado'), divinidad rectora de la temporada seca, el padre de su huaca Colqueyanac, como lo recordaba el "hechicero" Hernando Hacaspoma cuando recomendaba adorar "a el guaca colqueyanac porque decia que hera yjo del lliuiac y que nos diese agua” (Duviols 2003:454). Estos pocos datos sugieren que la cosmogonía andina repartía a los huacas en dos conjuntos genealógicos: los hijos del Sol, que ejercían su tutela sobre los agricultores de quebrada, y los hijos del Rayo, que protegían a los aillus que explotaban la puna ${ }^{4}$.

Según los procesos de Cajatambo, los huacas engendraron a su vez a los "mallquis" (mallki 'planta'), es decir a los fundadores de los aillus actuales, también llamados en estos documentos "primeros progenitores" o "primeros conquistadores", que se "plantaron" en los territorios que sus descendientes poseerían en común. Pedro Sarmiento, miembro de un aillu llacuaz de Hacas, refiere que "antiguamente en titicaca se repartieron las guacas que eran yndios vibos por todas las probincias y los dos dichos ydolos [Yanayacolca y su hermano Caruayacolca] vinieron a parar a este sitio de yanaqui y estos tubieron hijos que son los malquis siguientes que an mochado Tumasmalqui [...] y este tubo vn hijo Paquirachin malqui" (Duviols 2003:412). Una carta annua de Ocros, en la provincia de Huaylas, corrobora la información según la cual los mallquis fueron hijos de los huacas: "adoran vnas piedras movibles de particular hechura de que cuentan varias fabulas y cuerpos de sus progenitores gentiles 
cauesas de sus linajes que llaman mallquis y dizen son hijos de las tales piedras destas huacas o idolos" (Duviols 2003:451). Se distinguía por lo tanto a dos categorías de ancestros: los huacas, que no dejaron sus cuerpos ni sus objetos personales a las generaciones actuales -tal vez por ser demasiado antiguos-, y los mallquis, cuyos cuerpos y armas se conservaban. Llamaremos a los primeros "ancestros míticos" y a los segundos "ancestros auténticos" o "históricos". También nos parece acertada la denominación de "ancestros piedras" forjada por Meddens, McEwan y Pomacanchari (2010) para referirse a los ancestros míticos.

Las fuentes señalan la existencia de dos generaciones de ancestros huacas (Arriaga 1999 [1621]:101, 102). Ya lo señalaba el testimonio citado del cajatambino Pedro Sarmiento. En otro proceso, el reo Martín Jurado menciona en su confesión una casa "dedicada desde el tiempo antiguo para el ydolo yanca yacalva hijo de la huaca llamada huamanquilli que yanca yacalhua fue padre de quatro hijos malquis llamados Pomachaua Tunsuvilca huamanvica nuna Rupai de donde desiende todo este ayllo" (Duviols 2003:615). El calificativo de "ídolo" aplicado a Yanca Yacalhua debe entenderse como la probable traducción de waka en la declaración que Martín Jurado hizo en quechua. En efecto, este personaje disfrutaba de una "casa" (el "adoratorio" o "templo" de otras fuentes), contrariamente a los mallquis que se conservaban solamente en cuevas (machay), junto con los demás difuntos. Mencionemos por fin al huaca Apu Yuric, en Recuay, "que era una piedra con contrapuestos", que se conservaba en un peñol junto con su hijo Huayna Yuric "un idolo de piedra con facciones bien formadas" (Duviols 2003:759).

Al parecer, estas dos generaciones correspondían al doble nivel de integración social que existía en los Andes de entonces: el ayllu, coalición de familias nucleares, y el llaqta o confederación de aillus. En efecto, varias fuentes distinguen dos categorías de huacas según su relación con uno u otro de estos niveles. Una carta annua relativa a la provincia de Cajatambo explica que algunos huacas "son comunes a todo un Pueblo, otros de particulares aillos, o parentelas" (Duviols 2003:723). Otra апnиа, esta vez de Huancavelica, señala que los huacas de la segunda categoría eran llamados "ayllo huaca" (Polia Meconi 1999:329), es decir 'huacas de aillu'. El extirpador Pablo José de Arriaga también reconoció esta diferencia, pues distinguió los "huacas principales" de los "huacas menores" (Arriaga 1999 [1621]:56).
Francisco de Ávila, por su parte, utiliza varias veces en su sermonario en quechua las expresiones "hatun huacca" (hatun wak'a) "ídolo principal” (Ávila 1646:31, 47, 185, 512, 528, 549) y "Hatun marca Huacca" (hatun marka wak'a) "Idolo principal de vuestro pueblo" (Ávila 1646:333), retomando al parecer formulaciones indígenas para referirse a la divinidad tutelar de un llaqta, por contraste con los huacas de aillu ${ }^{5}$. Parece muy probable que los huacas principales, o hatun wak'a, fundaron los llaqta y que sus hijos, los ayllu wak'a, subdividieron en aillus el patrimonio paterno.

Es importante advertir que los huacas, o ancestros míticos, no eran forzosamente los verdaderos ascendientes de quienes les rendían culto. El autor indígena del manuscrito de Huarochirí cuenta cómo Tutayquiri, un "ancestro histórico", hijo del huaca Pariacaca, luego de conquistar parte de la provincia de Huarochirí y expulsar a sus primeros ocupantes -los yuncas-, repartió los huacas protectores del lugar -hasta entonces adorados por los yuncas- entre los aillus que lo seguían (Taylor 1999:315-317, cap. $24)^{6}$. Es un caso de adopción de ancestros míticos por los recién llegados a un lugar.

\section{Estatuillas Huacas}

Algunas fuentes señalan que el término waka wak'a se aplicaba también a objetos distintos a los hasta ahora mencionados. Según Garcilaso se llamaba "huaca" "a las piedrecitas y guijarros que hallan en los ríos o arroyos, con extrañas labores o de diversos colores, que se diferencian de las ordinarias" (Comentarios reales, lib. II, cap. 4). A este tipo de piedras pequeñas se refería al parecer Francisca Cochaquillay, testigo en un proceso de idolatrías seguido en 1556 en Cajamarquilla (prov. de Cajatambo), al declarar que la curandera Francisca Poma Carua tenía pequeñas piedras propiciatorias de la riqueza (o "guacanquis", es decir waqanki) denominadas "Pacha Guacam" (pacha wakan 'huaca de la ropa') "que da ropas y vestidos", "Colque Guacam" (qullqi wakan "huaca de la plata') "que da plata" y Micuy Guacam" (mikuy wakan 'huaca de la comida') "que da comidas" (Duviols 2003:175). Bartolomé Álvarez menciona esta categoría de huacas, que tenían "los hombres ricos que tienen ganado, haciendas y alguna nobleza de linaje" y que consistían en "figuras de carneros" de plata, oro, cobre o barro", distinguiéndolas de las huacas conservadas en los santuarios de altura, que define como huacas "de provincias, de reino y lo demás" 
(Álvarez 1998 [1588]:80). El mismo autor señala que sus dueños las llevaban consigo, las conservaban en sus casas o las enterraban en sus chacras. Asimismo, uno de los sermones del Tercero catecismo de 1585 puntualiza que "Huaquinijquichicca huc llampu rumi alli ricchallactam, huacaymi ñispa muchanquichic, huaquinmi cana collquemanta hichasca llamallacta huacaymi ñinquichic" "Algunos de ustedes adoran una piedra lisa de buena apariencia diciendo que es su huaca; otros consideran como su huaca a una llama hecha de plata' (Tercer Concilio de Lima 1985:561, f. 107r, nuestra traducción). A estos objetos familiares se refiere también Diego González Holguín en la primera entrada que dedica a wak'a en la sección quechua-español de su Vocabulario: "Huacca. Ydolos figurillas de hombres y animales que trayan consigo" (González Holguín 1608:159). Y en los siguientes artículos: "Huaccachascca collque. La plata escondida debaxo de tierra" (wak'achaŝqa qullqi "plata hecha wak'a'), "Huacca collque churascca collque, o ylla. El tesoro" (wak'a qullqi 'plata wak'a, churaŝqa qullqi 'plata guardada', illa 'brillo'), "Huacca o ylla collquecta churarini. Guardar plata atesorar, o poner en tesoro" (González Holguín 1608:159). Estas expresiones se refieren a estatuillas de plata que se enterraban (y que por eso eran consideradas por los españoles como "tesoros"). El lexicógrafo establece una equivalencia esclarecedora: wak'a qullqi significaría lo mismo que illa, un término que designa hoy en gran parte de los Andes peruanos a las pequeñas piedras zoomorfas que constituyen prototipos propiciatorios de la fecundidad del ganado. Sus dueños las hallaron en los cerros o los ríos, identificándolas por su apariencia extraña como dones de la divinidad dueña del espacio agreste. $\mathrm{Su}$ forma natural se subraya a veces mediante una intervención escultórica. Estos datos etnográficos sugieren que el llamar waka wak' $a$ a estos "amuletos" se debía a que procedían de la divinidad huaca y compartían su naturaleza. Waka wak'a no habría sido entonces el término que las designaba en propio, sino una denominación secundaria -con respecto a illa-, que incidía en que eran emanaciones pétreas de la interioridad o "alma" del cerro. Esta forma de designar dichas "estatuillas" permanece hoy en dos regiones: el valle del Mantaro, donde se conocen como waka las figuras zoomorfas de arcilla que se entierran en los corrales para propiciar la fecundidad de los rebaños (Ballón et al. 1992:179), y la provincia de Chachapoyas, donde la tradición oral llama waka-willka a los amuletos que las divinidades de los cerros ofrecen a las personas pobres y virtuosas (Taylor 2006:104).

Tanto las piedras huacas como las estatuillas huacas aparecen, por lo tanto, estrechamente vinculadas a las montañas: mientras que las primeras se conservaban en santuarios de altura, las segundas eran dones de la divinidad. Estos dos tipos de huacas correspondían a dos niveles de eficiencia: el del grupo social (sea el llaqta o el ayllu), para las piedras huacas, y el del individuo o la familia, para las estatuillas. Veremos ahora que el término waka wak'a permanece hoy en varios dialectos quechuas y aimaras como designación de alguno o algunos aspecto(s) de estos cerros divinos.

\section{Las Huacas Hoy en Día}

Hasta donde sabemos, son cinco las variedades del quechua y del aimara en las que se sigue usando el término waka wak'a:

1. El sur de Ecuador (provincias de Azuay, Cañar y Loja), donde waka designa una entidad femenina, también conocida como mama waka, que mora dentro del cerro (Zaruma Quishpelema 1989:125-126, 127) o en una peña situada en él (Lamadrid 1993). En la tradición oral, este personaje busca devorar al protagonista, le ofrece oro a cambio del sacrificio de un niño no bautizado o premia su inocencia y desinterés dándole riquezas (Zaruma Quishpelema 1989:125-126, 127).

2. El área dialectal huayla-conchuco (centro-norte del Perú), donde waka designa la fuerza fecundante que los cerros transmiten al ganado (Carranza Romero 2003:266), así como peñas de forma humana o animal que se encuentran en el espacio agreste (Parker 1976:185; Swisshelm 1972:162).

3. La región del Cuzco y de la zona quechuahablante del Collao, donde se califica de wak' $a$ a los lugares susceptibles de devorar a los transeúntes ${ }^{7}$.

4. En aimara meridional, wak'a designa grandes piedras antropomorfas y lugares de ofrenda al cerro (Apaza Suca et al. 1984:241; Huayhua Pari 2009:242; Van den Berg 1985:200).

5. En la zona quechua del sur de Bolivia, wak'a designa una potencia dadora de agua y multiplicadora del ganado, que reside en las lagunas (Nicolas et al. 2004:50, 144). 
En cambio, el término waka parece no existir en las variedades quechuas ayacuchana y del norte de Ecuador.

Como se observa, dos de los principales referentes antiguos del término, la piedra transportable y el santuario que la albergaba, se desconocen en la actualidad, con la excepción del área aimarahablante del Collao, donde algunas comunidades conservan todavía piedras huacas como símbolo de su identidad (Astvaldsson 1998; Janusek 2015). Esta cuasi ausencia debe atribuirse, por supuesto, a la destrucción de estos objetos y estructuras por la Iglesia ${ }^{8}$. Sin embargo, waka wak'a tiene en la actualidad un referente que la documentación histórica, obsesionada por el tema de los "ídolos", dejó en un segundo plano: ciertas rocas o peñas, de forma vagamente antropomorfa, que están en los cerros y parecen concentrar la potencia de estos. También se observa que los cerros, como divinidades, ya no son designados hoy como waka o wak'a -contrariamente p.ej., a Pariacaca o Huallallo Carhuincho en el Manuscrito de Huarochirí-, sino mediante denominaciones genéricas que varían según las regiones ( $а р и$ 'mayor', wamani, tayta urqu, etc.). La prédica cristiana, que durante varios siglos asimiló los huacas al demonio, es la probable causa de que se dejara de aplicar la categoría de waka wak'a a los cerros en su dimensión benéfica. Parece corroborarlo el hecho de que, en el quechua cuzqueño y del Collao -que estuvo particularmente expuesto al registro pastoral de la lengua-, wak'a siempre califica hoy a una entidad maléfica.

Veremos ahora que existen otros usos, antiguos y actuales, de waka wak'a, fuera del ámbito de lo sagrado. Debemos tomarlos en cuenta para sacar a luz el significado del término.

\section{Otros Usos y Significado}

Tanto las variedades modernas del quechua y del aimara como las fuentes antiguas registran empleos de wak'a en apariencia ajenos a los que hemos analizado hasta ahora. En la sección quechua-español de su Lexicón, Domingo de Santo Tomás ofrece la siguiente entrada: "Guacapungo.o caçaquero desdentado que le falta algun diente", que también figura de modo inverso en la parte español-quechua. Estas expresiones, en las que wak' $a$ actúa siempre como adjetivo, deben interpretarse como wak'a punku 'puerta wak'a' y q'asa kiru 'dentadura mellada' ${ }^{\prime}$. La segunda de ellas es todavía común en el quechua cuzqueño para referirse de modo elíptico a una persona a la que le falta un diente. Diego González Holguín las registra también: "Huaccapunco. El desdentado mellado por baldon, o cassaquiru" (González Holguín 1608:159; "Baldón" significaba 'injuria' o 'insulto'). El lexicógrafo jesuita ofrece ejemplos en que $w a k^{\prime} a$ se aplica a la nariz y al labio: "Huacca, checcta çinca [wak'a, ch'iqta sinqa] [...]. Hombre de nariz partida" (González Holguín 1608:159), "Chectaruna o huaca o succu [ch'iqta runa, wak'a, suk'u]. El q(ue) tiene el labio hendido" (González Holguín 1608:67). En los tres casos, wak' $a$ remite a un quiebre o una hendidura que divide un cuerpo -dentadura, nariz, labio- en dos partes. La acepción 'mella, hendidura' se conserva hoy en quechua cuzqueño: riru wak' a es la separación entre dos dedos y siki wak'a la raya del trasero (Mannheim y Salas Carreño 2015:55).

Wak'a calificaba también una entidad caracterizada por su división en dos partes (mediante una hendidura). González Holguín registra: "Huacca huachascca o yscayhuachasca. El varon, o la hembra nacidos de vn parto" (wak'a wachaŝqa 'parido wak'a', González Holguín 1608:159), en que los mellizos aparecen como partidos o escindidos. Del mismo modo, según Garcilaso, "llaman huaca al huevo de dos yemas" (Comentarios reales, lib. II, cap. 4). La noción de una partición reaparece en esta otra entrada del Vocabulario de González Holguín, aplicada a la persona que tiene seis dedos, es decir un dedo duplicado: "Huacca, o puma runa. Quando tiene seis dedos en manos y pies como leon" (González Holguín 1608:159). La noción de wak'a presentaba, por lo tanto, dos vertientes: la de 'mella, hendidura' (que separa dos partes de algo) y la de 'duplicado por partición'. Esta ambivalencia se manifiesta en otro ejemplo proporcionado por el lexicógrafo jesuita, en que el wak'a runa ('individuo $\left.w a k^{\prime} a^{\prime}\right)$ puede ser, según el caso, un animal con una pata menos o más: "Huacca runa. Carnero, o qualquier bestia monstruosa que tiene mas, o menos miembros" (González Holguín 1608:159). Lo mismo sucedía en aimara: "Huaka [...] Monstro, animal que nace con menos o mas partes dé las q(ue) suele dar naturaleza"; "Huaka haque, Canra, \&c. Hombre o carnero assi nacido" (Bertonio 1612, II:143).

En estos ejemplos, wak' $a$ actúa preferentemente como calificativo, con las funciones gramaticales de adjetivo o atributo, según los casos. Empleado como sustantivo, presenta el significado de 'algo $w a k$ ' $a$ ' 10 . En efecto, como lo hemos visto, waka wak' a se refiere y refería a una cualidad: la de estar partido en dos (lo que podía resultar en una duplicación).

La presencia de un rasgo glotal en la forma cuzqueño-boliviana del término, así como en aimara, 
corrobora la interpretación de su significado primario como 'partidura, hendidura, mella'. Como lo ha mostrado B. Mannheim (1991:177-207), el rasgo glotal se asocia, en el quechua cuzqueño, a las nociones de golpe seco, brusca eyección, torsión, dureza, fractura, pequeñez y estrechez, así como a todo lo que es plano, liso y luminoso. En los ejemplos proporcionados por Santo Tomás y González Holguín, wak'a actúa como parasinónimo de términos que también llevan un rasgo glotal y comparten la noción de fractura: $q$ 'asa 'mella', ch'iqta 'rajadura' y suk'u 'rotura por estiramiento'. Trataremos de entender ahora por qué se consideró a las manifestaciones pétreas de los ancestros míticos como "partiduras".

\section{Las Huacas, Dobles Líticos del Ancestro Mítico}

El predicador Fernando de Avendaño recordaba lo siguiente a su auditorio: "Hamauttaiquichiccuna, cai Huaccacuna manaracc rumi captin, manaracc Huacca tucuptincupas, ñoccanchic hina aichayocc, tulluyocc runam carccancu, ñincum". Es decir, según su propia traducción: "Vuestros Sabios dizen, que estas Huacas antes que fueran piedras, y se conuirtieran en Huacas, eran hombres como nosotros de carne, y huessos" (Avendaño 1649:43r-43v). La formulación quechua no deja lugar a ambigüedades: literalmente (manaraq wak'a tukuptinkupas 'antes de que se volvieran huacas'), estos poderosos hombres del pasado no fueron huacas cuando vivían, sino que se convirtieron en tales al final de su existencia humana.

$\mathrm{Ni}$ las piedras ni las estatuillas a las que nos hemos referido solían presentar una forma mellada o hendida. Por lo tanto, debemos entender que su calificación como wak'a fue una alusión a su estado de "partiduras" de otra entidad, del mismo modo como un mellizo o un sexto dedo aparecen como separados o duplicados con respecto a su par. Las fuentes no contienen referencias precisas al proceso de metamorfosis lítica de los ancestros míticos, pero sabemos que al morir cada ancestro histórico se había duplicado en una piedra llamada "huanca" (Duviols 2016b, 2016c), es decir wanka en el centro del Perú y wank'a en quechua cuzqueño. Mayores que las piedras huacas, las huancas estaban plantadas en el suelo, manifestando la toma de posesión masculina y fecunda del territorio por el ancestro conquistador (Duviols 2016b [1978], 2016c [1979]). El hecho de que ambos tipos de piedra fueran manifestaciones ancestrales y que sus nombres presentaran una semejanza (hasta en la posesión de un rasgo glotal), sugiere que las piedras huacas fueron el producto de un proceso análogo al que dio origen a las huancas, es decir de una eyección y petrificación de la fuerza vital del ancestro en el momento de su muerte (sobre el símbolo de la piedra y la petrificación del pasado, véase Howard 2006).

\section{Origen Histórico-Cultural del Culto a los Ancestros Piedras}

¿A qué etapa histórica se remonta el culto de las piedras huacas? En los siglos XVI y XVII, la tradición indígena conservaba todavía un recuerdo de las circunstancias en que tal o cual ancestro mítico se había manifestado a los vivos para reclamar que se instituyera su culto a través de una huaca. Tenemos al respecto dos testimonios principales. Según Bartolomé Álvarez, el ancestro mítico aparecía a una persona pidiéndole que se le rindiera culto "en el sepulcro donde estaba enterrado [...] o en algún peñasco o lugar dificultoso; o decía: "esta piedra, ¿vesla aquí que está de tal forma? Ésta toma y llévala a tu padre o parientes, y di que la pongan en tal lugar y que allí me ofrezcan"'" (Álvarez 1998 [1588]:76). En este caso, el ancestro mismo designaba la piedra que lo materializaría. En unos casos, esta presentaba una forma llamativa -como lo señalaba Garcilaso, obviando sin embargo la intervención de la divinidad-; en otros, el ancestro pedía que se haga en piedra "una figura a [...] semejanza" de él (Álvarez 1998 [1588]:76). El capítulo 20 del Manuscrito de Huarochirí ofrece el relato de una de estas apariciones: al labrar su chacra, una mujer encontró una piedra y la arrojó a un lado; pero la piedra regresó al mismo lugar, repitiéndose el mismo prodigio varias veces; la labradora la llevó entonces a su pueblo, donde el huaca Cataquillay logró hacer que la piedra hablara y revelara que era Llocllayhuancupa, uno de los hijos de Pachacámac (Taylor 1999:246-249). Tales como las refieren las fuentes, estas revelaciones no parecen situarse en tiempos muy antiguos. En el caso de Llocllayhuancupa, el autor indígena señala expresamente que el descubrimiento de la piedra tuvo lugar en tiempos del Inca (Taylor 1999:246-247). Si nos atenemos a la información arqueológica actualmente conocida, podemos atribuirlas en efecto a dicha época, pues las piedras huacas hasta hoy descubiertas pertenecen todas a ella. Si bien los apologistas cristianos del imperio cuzqueño, como Garcilaso o Pachacuti Yamqui hacen remontar la "idolatría" de las huacas a tiempos anteriores a dicho imperio, otros cronistas, 
como Huaman Poma, atribuyen su institución a los incas. Tomada literalmente, la afirmación de este último autor podría ser cierta.

Los incas, en efecto, ejercieron un control estricto sobre dicho culto: las piedras huacas que se descubrían debían ser llevadas al Cuzco, donde permanecían algún tiempo antes de ser devueltas a su santuario local, en una cumbre, donde recibían ofrendas anuales de parte del Inca (Álvarez 1998 [1588]:74). En otros casos, tal vez cuando el soberano cooptaba un culto preexistente, la piedra era donada por él a cambio de la anterior materialización de la divinidad, que era llevada al Cuzco. Francisco de Ávila refiere que un habitante de San Damián, en la provincia de Huarochirí, le enseñó una "piedra azul" que el Inca había dado a sus "mayores" en reemplazo de un "ídolo" de oro que había sido llevado a la capital. Acompañado de ropa miniaturizada, la piedra materializaba al huaca Macahuisa, a quien la hija de ese hombre estaba "dedicada por mujer" (Ávila 1918 [1648]). En su "Tratado y aueriguacion", Polo de Ondegardo confirma que los incas retuvieron como rehenes en el Cuzco las principales huacas de cada provincia (Polo de Ondegardo 1985 [1585]). Huaman Poma representa un grupo de ellas en la capital, interrogadas por Tupa Yupanqui, mientras Huanacauri, huaca de los cuzcos, domina la escena desde las alturas del cerro homónimo (Huaman Poma 1936:261).

Otro indicio importante a favor de la tesis de un origen inca del culto de las piedras huacas es que el significado primario del término, el de 'partidura', solo se conserva hoy en el quechua cuzqueño. Ello sugiere que procede de esta variedad de la lengua y que no existió con ese significado en las otras ramas de la lengua.

\section{Conclusión}

No hubo en quechua ni en aimara un concepto similar al de 'sagrado', tal como lo entiende la antropología, es decir como algo separado de lo profano. El término waka wak'a calificaba -y sigue calificando en quechua cuzqueño- cuerpos que presenta(ba)n una forma hendida, sea por ausencia de uno de sus constituyentes (una mano o pata a la que le falta un dedo, una dentadura incompleta), por división (la nariz partida, el labio leporino, la raya del trasero) o por duplicación (los mellizos o un dedo adicional). Aplicado a la reliquia pétrea de un ancestro mítico, waka wak'a se refería al doble lítico de su persona que se había formado en el momento de la muerte. Solo por extensión o metonimia, el mismo término designaba o calificaba también: (1) al pequeño santuario edificado para alojar al "alma" petrificada (como si fuera su nueva envoltura corporal); (2) a los ancestros míticos cuando vivían (de acuerdo a una denominación retrospectiva); (3) a los pequeños objetos donados por estas entidades para actuar como prototipos generativos de riqueza familiar (y que tal vez constituían ellos también desdoblamientos de su ser).

Aunque las fuentes no lo mencionan muy claramente, es posible que los hablantes también llamaran waka $w a k^{\prime} a$ a las peñas en que los ancestros míticos residían en el presente. Ello explicaría el uso actual de esta palabra en las variedades quechuas de Ancash y de Bolivia, así como en aimara, para referirse a ellas. El capítulo 17 del Manuscrito de Huarochirí explica que Pariacaca vive dentro de una peña del cerro Huamayaco: Chaypitaqŝi wakinnin wawqinkunapaŝ chay qaqa ñiŝqanchikman yaykuŝsaŝ "kaypim tiyaŝaq; kaymantam muchawanki" ñispa chay qaqapi llaqtachakurqan. "Cuando entró con los demás hermanos en esa peña, dijo: "Voy a quedarme aquí; desde aquí ustedes me adorarán" y allí en esa peña se estableció como huaca local" (Taylor 1999:222-223).

Dado que cada piedra huaca era la concreción de una potencia individualizada y dotada de una mito-historia propia, los huacas deben considerarse como dioses, es decir como entidades que se definen por un poder que excede de modo absoluto al de los humanos. Es precisamente lo que quiso ocultar Garcilaso, defensor de la tesis del cuasi monoteísmo de los antiguos peruanos, induciendo a que los investigadores modernos vieran en "huaca" un numen impersonal y difuso.

La organización de este culto por los incas fue al parecer el correlato religioso de las migraciones masivas que dirigieron. Los colonos necesitaban conservar un vínculo tangible con su territorio de origen, al mismo tiempo que una divinidad físicamente presente, y por lo tanto eficiente, en su nuevo lugar de vida. La centralización temporal o permanente de los huacas -o de una de sus materializaciones- en el Cusco era una manera de rearticular alrededor de la capital un espacio simbólico imperial fragmentado por las deportaciones.

Agradecimientos: A los revisores anónimos por la lectura del manuscrito. 


\section{Referencias Citadas}

Álvarez, B. 1998 [1588]. De las Costumbres y Conversión de los Indios del Perú. Memorial a Felipe II. Edición de $\mathrm{M}^{\mathrm{a}}$ del C. Martín Rubio, J.R. Villarías Robles y F. del Pino Díaz. Ediciones Polifemo, Madrid.

Anónimo 1586. Arte y Vocabvlario en la Lengva General del Perv Llamada Quichua, y en la Lengua Española. Antonio Ricardo, Lima.

Apaza Suca, N., K. Komarek, D. Llanque Chana y V. Ochoa Villanueva 1984. Diccionario Aymara - Castellano, Arunakan Liwru Aymara - Kastillanu. Proyecto Experimental de Educación Bilingüe, Lima - Puno.

Astvaldsson, A. 1998. The powers of hard rock: Meaning, transformation and continuity in cultural symbols in the Andes. Journal of Latin American Cultural Studies 7 (2):203-223.

Arriaga, P.J. de 1999 [1621]. La Extirpación de la Idolatría en el Perú. Centro de Estudios Regionales Andinos Bartolomé de las Casas, Cuzco.

Avendaño, F. De 1649. Sermones de los Misterios de Nvestra Santa Fe Catholica, en Lengva Castellana, y la General del Inca. Jorge López de Herrera, Lima.

Ávila, F. De 1646. Tratado de los Evangelios, que Nuestra Madre la Iglesia Propone en Todo el Año..., vol. 1. Jorge López de Herrera, Lima.

Ávila, F. De 1918 [1648]. Prefación al libro de los sermones, o homilías en la lengua castellana y la índica general quechua. En Informaciones Acerca de la Religión y Gobierno de los Incas..., editado por H. Urteaga y C. Romero, pp. 57-98. Imprenta Sanmartí, Lima.

Ballón Aguirre, E., R. Cerrón-Palomino y E. Chambi Apaza 1992. Vocabulario Razonado de la Actividad Agraria Andina. Terminología Agraria Quechua. Centro de Estudios Regionales Andinos Bartolomé de Las Casas, Cuzco.

Betanzos, J. de 2015 [1551]. Suma y Narración de los Incas. Edición de F. Hernández Astete y R. Cerrón-Palomino. Fondo Editorial Pontificia Universidad Católica del Perú, Lima.

Bertonio, L. 1612. Vocabvlario de la Lengua Aymara. Francisco del Canto, Juli.

Carranza Romero, F. 2003. Diccionario Quechua Ancashino Castellano. Edición y prólogo de W. Lustig. Iberoamericana, Vervuert, Frankfurt.

Cerrón-Palomino, R. 2013. Tras las Huellas del Inca Garcilaso. El Lenguaje como Hermenéutica en la Comprensión del Pasado. Latinoamericana Editores, CELACP, Revista de Crítica Literaria Latinoamericana, Boston.

Cieza de León, P. 1995 [1553]. Crónica del Perú. Primera parte. Fondo Editorial Pontificia Universidad Católica del Perú - Academia Nacional de Historia, Lima.

Duviols, P. 1957. Un inédit de Cristobal de Albornoz: La instrucción para descubrir todas las guacas del Pirú y sus camayos y haciendas. Journal de la Société des Américanistes 56 (1):7-39.

Duviols, P. 1971. La Lutte Contre les Religions Autochtones dans le Pérou Colonial. "L'expiration de l'idôlatrie" entre 1532 et 1660. Institut Français d'Études Andines, Lima.
Duviols, P. 2003. Procesos y Visitas de Idolatrias. Cajatambo Siglo XVII. Revisión paleográfica de L. Gutiérrez Arbulú y L. Andrade Ciudad, selección de los textos y estudios históricos por P. Duviols, textos quechuas editados, traducidos y anotados por C. Itier. Institut Français d'Études Andines, Fondo Editorial Pontificia Universidad Católica del Perú, Lima.

Duviols, P. 2016a [1973]. Huari y llacuaz. Agricultores y pastores: un dualismo prehispánico de oposición y complementariedad. En Escritos de Historia Andina, editado por J. Flores y C. Itier, pp. 81-145. Biblioteca Nacional del Perú, Instituto Francés de Estudios Andinos, Lima.

Duviols, P. 2016b [1978]. Un simbolismo andino del doble: la litomorfosis del ancestro. En Escritos de Historia Andina, editado por J. Flores y C. Itier, pp. 167-174. Biblioteca Nacional del Perú, Instituto Francés de Estudios Andinos, Lima.

Duviols, P. 2016c [1979]. Un simbolismo de la ocupación, el ordenamiento y la explotación del espacio: el monolito "huanca" y su función en los Andes prehispánicos. En Escritos de Historia Andina, editado por J. Flores y C. Itier, pp. 175-206. Biblioteca Nacional del Perú, Instituto Francés de Estudios Andinos, Lima.

Flores Ochoa, J. 1971. La wak'a awicha Anselma. Allpanchis Phuturinqa 3 (3):68-78.

González Holguín, D. 1608. Vocabvlario de la Lengva General de Todo el Perv Llamada Qquichua, o del Inca. Francisco del Canto, Lima.

Howard, R. 2006. Rumi: An ethnolinguistic approach to the symbolism of stone(s) in the Andes. En Kay Pacha. Cultivating Earth and Wáter in the Andes, editado por P. Dransart, pp. 233-245. BAR International Series 1478, Oxford.

Huaman Poma de Ayala, F. 1936 [1615?]. Nueva Corónica y Buen Gobierno, Institut d'Ethnologie, Paris.

Huayhua Pari, F. 2009. Diccionario Bilingüe Polilectal Aimara Castellano, Castellano - Aimara. Universidad Nacional Mayor de San Marcos, Lima.

Janusek, J.W. 2015. Of monoliths and men: human-lithic encounters and the production of an animistic ecology at Khonkho Wankane. En The Archaeology of Wak'as. Explorations of the Sacred in the Pre-Columbian Andes, editado por T.L. Bray, pp. 335-365. University Press of Colorado, Boulder.

Lamadrid, E.R. 1993. Treasures of the Mama Huaca: Oral Tradition and Ecological Consciousness in Chinchaysuyu. University of New Mexico, Latin American Institute, Albuquerque.

Las Casas, B. De 1992 [1565]. De Thesauris, editado por Á. Losada. Obras Completas Vol. 11.1. Alianza Editorial, Madrid.

Mannheim, B. 1991. The Language of the Inka Since the European Invasion. University of Texas Press, Austin.

Mannheim, B. y G. Salas Carreño 2015. Wak' as. Entifications of the Andean sacred. En The Archaeology of Wak'as. Explorations of the Sacred in the Pre-Columbian Andes, editado por T.L. Bray, pp. 47-72. University Press of Colorado, Boulder.

McEwan, C. 2005. Ordering the sacred and recreating Cuzco. En The Archaeology of Wak'as. Explorations of the Sacred in the Pre-Columbian Andes, editado por T.L. Bray, pp. 265-291. University Press of Colorado, Boulder. 
Meddens, F., C. McEwan y C. Pomacanchari 2010. Inca "stone ancestors" in context at a high-altitude usnu platform. Latin American Antiquity 21 (2):173-194.

Nicolas, V., S. Zegarra Quintanilla y A. Puma Layme 2004. Ayllusninchismanta Parlarispa. Antología de Historias Orales de Tinkipaya. Programa de Investigación Estratégica en Bolivia, La Paz.

Parker, G. 1976. Gramática Quechua Ancash-Huailas. Ministerio de Educación, Instituto de Estudios Peruanos, Lima.

Polia Meconi, M. 1999. La Cosmovisión Religiosa Andina en los Documentos Inéditos del Archivo Romano de la Compañía de Jesús, 1581-1752. Fondo Editorial Pontificia Universidad Católica del Perú, Lima.

Polo de Ondegardo, J. 1985 [1585]. Los errores y svpersticiones de los Indios sacadas del Tratado y aueriguacion que hizo el Licenciado Polo. En Doctrina Christiana y Catecismo para Instrucción de Indios, facsímil del texto trilingüe, ff. 7-16. Consejo Superior de Investigaciones Científicas, Madrid.

San Pedro, J. de 1992 [1560]. La Persecución del Demonio. Crónica de los Primeros Agustinos en el Norte del Perú. Manuscrito del Archivo de Indias transcrito por E.E. Deeds, Introducción de T. Van Ronzelen, estudios preliminares de L. Millones, J.R. Topic y J.L. González. Editorial Algazara, Málaga.
Santo Tomás, D. De 1994 [1560]. Lexicón, o Vocabulario de la Lengua General del Perv. Edición facsimilar. En Grammatica o Arte de la Lengua General de los Indios de los Reynos del Peru. Estudio y transliteración por R. Cerrón-Palomino. Agencia Española de Cooperación Internacional, Ministerio de Relaciones Exteriores de España, UNESCO ediciones, Madrid.

Swisshelm, G. 1972. Un Diccionario del Quechua de Huaraz. Estudios Culturales Benedictinos, Huaraz.

Taylor, G. 1999. Ritos y Tradiciones de Huarochirí. Segunda edición revisada. Instituto Francés de Estudios Andinos, Banco Central de Reserva del Perú, Universidad Particular Ricardo Palma, Lima.

Valderrama, R. y C. Escalante 1992. Ñuqanchik Runakuna Nosotros los Humanos. Testimonios de los Quechuas del Siglo $X X$. Centro de Estudios Regionales Andinos Bartolomé de Las Casas, Cuzco.

Van Den Berg, H. 1985. Diccionario Religioso Aymara. CETA, IDEA, Iquitos

Zaruma Quishpelema, B. 1989? Hatun Cañar Apunchicunamanta Nishcallata Yuyashca. Mito y Creencias de Hatun Cañar. Radio La Voz de Ingapirca, Cuenca.

\section{Notas}

1 Estos procesos registran las declaraciones de los testigos y reos indígenas, inicialmente formuladas en quechua y traducidas de inmediato al español para su traslado escrito. En cuanto al uso de nociones quechuas, estos documentos presentan, por lo tanto, un alto grado de fidelidad al discurso original de los declarantes.

2 Inti yaya, punĉaw yaya, waka churiyuq yaya, kaymi kuka, kaymi aswa, kaymi sara, kaymi haka, kayta mikuy, upyay 'Padre sol, padre día, padre progenitor de los huacas, aquí tienes coca, aquí tienes chicha, aquí tienes maíz, aquí tienes cuy, come y bebe esto' (nuestra transliteración y traducción)

3 Inti yaya, punĉaw yaya, waka churiyuq yaya, kaymi aswa, sara, mikuy kayta, upyay 'Padre sol, padre día, padre progenitor de los huacas, aquí tienes chicha y maíz, come y bebe esto'.

4 Sobre el dualismo social y religioso "huari" / "llacuaz", véase Duviols 2016a [1973].

5 En la segunda denominación, hatun marka wak'a, el término marka -que significaba originalmente 'lugar elevado' y designaba en toda la sierra los pueblos encumbrados del periodo Intermedio Tardío- designa los pueblos de reducción coloniales y su territorio.

6 Véase también el caso de Llacsamisa, que hizo otro tanto al conquistar otro sector del terrritorio huarochirano (Taylor 1999:401, cap. 31)

7 En 1608, Diego González Holguín ya registra un empleo muy parecido a los usos modernos de dicha zona: "Huaccam chaypi, o huaccam chayca ama yallisunchu. No passemos que es lugar peligroso". Wak'am chaypi o wak'am chayqa, ama yalliŝunchu. Tal vez por extensión, se aplica el mismo calificativo a fenómenos como el "mal viento" (wak'a wayra), el Rayo (wak'a Santiago) bajo su aspecto castigador o cualquier animal sobrenatural susceptible de comer física o anímicamente a una persona (Valderrama y Escalante 1992:23).

8 Hasta donde sabemos, la bibliografía ofrece un solo caso de culto actual a una piedra huaca (Flores Ochoa 1971).

9 La variedad de quechua descrita por el dominico es el antiguo quechua cuzqueño tal como lo habían adquirido las elites provincianas del Tahuantinsuyo. El modelo lingüístico que estas buscaban reproducir tenía, por lo tanto, los rasgos glotal y aspirado, motivo por el cual los restituimos en la transliteración.

10 "In both the deformity and sacred senses of wak'a, it is an attribute. But it is important to recognize that in Quechua, unlike English, attributes are also ambivalent as a grammatical category, so wak'a can modify a noun, but it can also be used in place of a noun. Wak'a alone would thus mean 'a wak'a thing"' (Mannheim y Salas Carreño 2015:55). Recuérdese que la mayoría de los lexemas del quechua son polivalentes en cuanto a categorías gramaticales, es decir pueden usarse como sustantivo, verbo o adjetivo (Mannheim y Salas Carreño 2015:55). 
